\title{
Antimicrobial activity of $L$. plantarum, isolated from a traditional lactic acid fermentation of table olives
}

\author{
Amélia Delgado $^{\mathrm{a} *}$, Dulce Brito ${ }^{\mathrm{a}, \mathrm{b}}$, Pedro FeVEreiro ${ }^{\mathrm{a}, \mathrm{c}}$, \\ Cidália PEREs ${ }^{\mathrm{a}, \mathrm{b}}$, José FigueIREdo MARQues ${ }^{\mathrm{a}, \mathrm{b}}$ \\ a Instituto de Tecnologia Química e Biológica, Quinta do Marquês 2780-505 Oeiras, Portugal \\ b Estação Agronómica Nacional, Instituto Nacional de Investigação Agrária, \\ Quinta do Marquês 2780-505 Oeiras, Portugal \\ ${ }^{\mathrm{c}}$ Instituto de Biologia Experimental e Tecnológica, Quinta do Marquês 2780-505 Oeiras, Portugal
}

\begin{abstract}
Lactobacillus plantarum strain LB17.2b, isolated from traditional table olive fermentation has been shown to produce thermostable antibacterial proteins. At $\mathrm{pH} 6.5$, the proteinaceous fraction obtained from culture supernatant was active against Enterococcus faecalis and against natural competitors of $L$. plantarum from olive fermentation brines. Bioactivity was quantified against Weissella paramesenteroides DSM20288 using the critical dilution method by a regression procedure. This bioactivity has been found to be growth-associated indicating a primary metabolite kinetics. Ultrafiltration studies with supernatants from different fermentation times have been carried out. A twofold increase in the activity of the retentate from the $30 \mathrm{~kg} \cdot \mathrm{mol}^{-1}$ cut-off membrane was observed, by comparison with the total activity applied to this membrane (culture supernatant). The addition of the filtrate to this retentate caused a marked drop in activity, most probably associated with the presence of an inhibitor. These studies also demonstrated the presence of another antibacterial proteinaceous compound showing a wider inhibitory spectrum and produced during culture stationary phase. In the presence of lactic acid ( $\mathrm{pH}$ 3.7), these antimicrobial proteinaceous compounds have been found to inhibit Gram-negative human pathogens, probably by a synergistic effect. At the present time one bacteriocin-like compound was isolated, showing a molecular mass of approximately $50 \mathrm{~kg} \cdot \mathrm{mol}^{-1}$. The presence of another compound of different properties and with a molecular mass between 3 and $10 \mathrm{~kg} \cdot \mathrm{mol}^{-1}$ was also detected.
\end{abstract}

antimicrobial activity / bacteriocin / lactic acid / Lactobacillus plantarum

Résumé - Activité antimicrobienne de L. plantarum isolé d'une fermentation lactique traditionnelle d'olives de table. La souche de Lactobacillus plantarum LB17.2b, isolée à partir de la fermentation traditionnelle des olives de table, a montré la capacité à produire des protéines antimicrobiennes thermostables. À $\mathrm{pH} 6.5$, la fraction protéique obtenue à partir du surnageant de la culture était active contre Enterococcus faecalis et contre les compétiteurs naturels de L. plantarum,

* Correspondence and reprints

Tel.: (351) 2144695 57; fax: (351) 2144112 77; e-mail: ameliad @ itqb.unl.pt 
présents dans les saumures de fermentation. La bioactivité a été quantifiée contre Weissella paramesenteroides DSM20288 par la méthode de dilution critique, utilisant une procédure de régression. Cette bioactivité a été démontrée être associée à la croissance, indiquant une cinétique de métabolite primaire. Des études d'ultrafiltration avec le surnageant à différents temps de fermentation ont été effectuées. On a observé une augmentation d'un facteur deux de l'activité du rétentat obtenu avec la membrane de seuil de coupure $30 \mathrm{~kg} \cdot \mathrm{mol}^{-1}$ en comparaison à l'activité totale appliquée sur la même membrane (surnageant de la culture). L'addition du filtrat à ce rétentat a occasionné une diminution remarquable de l'activité, probablement associée à la présence d'un inhibiteur. Ces études ont démontré aussi la présence d'un autre composant protéique antimicrobien avec un spectre d'inhibition plus large et qui est produit pendant la phase stationnaire de la culture. En présence de l'acide lactique ( $\mathrm{pH} 3,7)$, ces protéines antimicrobiennes permettent d'inhiber des pathogènes humains Gramnégatifs, probablement grâce à un effet synergique. Un composant du type bactériocine, ayant une masse moléculaire d'environ $50 \mathrm{~kg} \cdot \mathrm{mol}^{-1}$, a été isolé. La présence d'un autre composant, ayant de propriétés différentes et une masse moléculaire entre 3 et $10 \mathrm{~kg} \cdot \mathrm{mol}^{-1}$, a été également détectée.

activité antimicrobienne / bactériocine / acide lactique / Lactobacillus plantarum

\section{INTRODUCTION}

Lactobacillus plantarum has been known to play a preponderant role in many spontaneous processes of table olive fermentations. Therefore, this species has been extensively studied with the aim of its use in starters. The ability to produce bacteriocins is an important factor for strain selection, strongly contributing to increasing the quality and the safety of the product.

The inhibitory action of lactic acid bacteria $(\mathrm{LAB})$ is due to the accumulation of main primary metabolites (lactic and acetic acids, ethanol and carbon dioxide) as well as to the production of other antimicrobial compounds, such as formic and benzoic acids, hydrogen peroxide, diacetyl, acetoin and bacteriocins [12, 13]. According to Piard and Desmazeaud [12], the production levels and the proportions among those compounds depend on the strain, medium composition and physical parameters. LAB are generally fermentative organisms although oxygen-tolerant and according to Roger et al. [14], the presence of oxidants strongly affects the nature of end-products of their metabolism. Under aerobic conditions, the accumulation of extra antimicrobial compounds may occur. Besides the production of hydrogen peroxide, the peroxidases accumulated in the cell can catalyse the oxidation of some metabolites such as aldehydes to toxic compounds. Diacetyl, acetoin and by-products of metabolism with less than $1000 \mathrm{~g} \cdot \mathrm{mol}^{-1}$ are referred to by Piard and Desmazeaud [13] as often showing a wide inhibitory spectrum, including Gram-negative bacteria. Reuterin [17] is a typical example of such substances.

Bacteriocins are another important group of antimicrobial compounds. Bacteriocins are an ill-defined group of extracellularly released proteinaceous antimicrobial substances, produced by a wide range of bacterial species, generally active against closely related bacteria and against which the producer strain has some mechanism(s) of specific protection. Main properties, classification and mode of action of bacteriocins produced by LAB are reviewed by Klaenhammer [7], Jack et al. [5] and Moll et al. [10].

The overall accumulation of all types of inhibitory compounds most probably play an important role in survival mechanisms.

The objective of the present work is to study the overall antibacterial activity of Lactobacillus plantarum LB17.2b in order 
to distinguish the role played by bacteriocin-like compounds from other inhibitory substances.

\section{MATERIALS AND METHODS}

\subsection{Bacterial cultures and media}

Lactobacillus plantarum strain LB17.2b was isolated from an olive brine fermentation at Alentejo, Portugal. All tested lactic acid bacteria were isolated from olive brines. Other bacteria were hospital isolates (human pathogens) or they have been obtained from lab collections (spoilage bacteria). All strains have been preserved frozen at $-20^{\circ} \mathrm{C}$. For most purposes, before experimentation stock cultures were propagated twice by adding $1 \% \mathrm{v} / \mathrm{v}$ inoculum into adequate broth media and incubated aerobically, without agitation, for 12 to $24 \mathrm{~h}$ at their optimum temperature. Lactic cultures were grown in MRS broth (Merck Mikrobiologie, Darmstadt, Germany) while all other tested bacteria were grown in Tryptic Soy Broth (Merck Mikrobiologie). For the detection of antagonistic activity MRS or TSB containing only $0.2 \%$ glucose (Merck Mikrobiologie) and $0.75 \%$ agar (Merck Mikrobiologie) were used.

\subsection{Detection of antimicrobial activity}

A diffusion assay was used for this purpose. Samples were laid in drops over the agar or inside wells. In all of the cases, the plates were prepared by pouring $3.5 \mathrm{~mL}$ of modified MRS or TSA agar containing $6.5 \mu \mathrm{L}$ of a cell suspension, carrying $3 \times$ $10^{7} \mathrm{cfu} \cdot \mathrm{mL}^{-1}$ over $25 \mathrm{~mL}$ of the same agar. For the evaluation of inhibitory spectrum $10 \mu \mathrm{L}$ of each sample and corresponding controls were laid over the agar containing each of the tested organisms. In the case of the well diffusion assay, $3 \mathrm{~mm}$ diameter wells ( $38 \mu \mathrm{L}$ capacity) were made after overlay solidification, by the use of an autoclave sterilised metal cylinder. After suitable incubation, inhibition zones were observed. Each assay was performed in duplicate.

\subsection{Bioactivity quantification}

A modified critical dilution method was used [9]. Serial two-fold dilutions of neutralised sterile samples were applied in wells of modified MRS plates inoculated with Weissella paramesenteroides DSM20288, according to the procedure described above. The diameter of each inhibition zone was measured twice in perpendicular directions by the use of a calliper of $0.1 \mathrm{~mm}$ precision (Dial 15-Tajima, Japan) with the plate resting on a colony counter with amplification and illumination (Gallenkamp, Leics., UK). Each assay was performed in duplicate. An aqueous solution of nisin (Sigma-Aldrich, Steinheim, Germany) was used as positive control and suitable negative controls were also performed for each test.

\subsection{Production of antimicrobial compounds}

To determine biomass and product formation profiles, each one of the $50 \mathrm{~mL}$ screw cap flasks (Schott Scientific Glass Inc., Parkersburg-WV, USA) containing $40 \mathrm{~mL}$ of MRS broth was inoculated with $40 \mu \mathrm{L}$ of a stationary phase culture of L. plantarum LB17.2b. All flasks were incubated in a $30{ }^{\circ} \mathrm{C}$ water bath (JP Selecta SA, Barcelona, Spain) with a very slight agitation (50 rpm) to homogenise temperature. Every 20 to $60 \mathrm{~min}$ duplicate flasks were withdrawn to measure OD $600 \mathrm{~nm}, \mathrm{pH}$ and to prepare culture supernatant, as described below. Accumulation of antimicrobial compounds was evaluated in neutralised supernatants by the well diffusion assay against Weissella paramesenteroides DSM20288 as the test organism. Biomass was calculated from the plot: culture OD $600 \mathrm{~nm}$ vs. dry weight of cells in $\mathrm{g} \cdot \mathrm{L}^{-1}$. For general purposes (as for most purification trials), $800 \mathrm{~mL}$ of broth contained in $1 \mathrm{~L}$ flasks (of 
the same type as above) were inoculated with $8 \mathrm{~mL}$ of culture suspension, homogenised and allowed to grow in an incubator for $12 \mathrm{~h}$ under static conditions.

\subsection{Preparation of crude extracts}

Lactobacillus plantarum strain LB17.2b was allowed to grow for the desired time, after which cells were separated by centrifugation at $10000 \mathrm{~g}$ for $15 \mathrm{~min}$. Supernatant was then heated in an autoclave for $5 \mathrm{~min}$ at $100{ }^{\circ} \mathrm{C}$, cooled in ice and filtered through a syringe filter of $0.22 \mu \mathrm{m}$ pore (Gelman Acrodisc 13, Pall Corp., Ann Arbor, USA). For most purposes the $\mathrm{pH}$ was adjusted to 6.5 with $\mathrm{NaOH} 10 \mathrm{~mol} \cdot \mathrm{L}^{-1}$ prior to filter sterilisation. The solution thus obtained has been designated as Cell Free Supernatant (CFS).

\subsection{Ultrafiltration studies}

A volume of $60 \mathrm{~mL}$ of CFS was prepared from culture media of each selected incubation time (namely 12, 24, 48 and $72 \mathrm{~h}$ ) and it was divided into $10 \mathrm{~mL}$ portions and filtered sequentially through ultrafiltration membranes of decreasing porosities, corresponding to molecular mass of 30,10 and $3 \mathrm{~kg} \cdot \mathrm{mol}^{-1}$ respectively (Centricon, Amicon Corp., Beverly-MA, USA). The devices were operated according to manufacturers' instructions. All devices and caps were previously weighted and numbered. Retentate and filtrate volumes were evaluated from weights assuming a density of one for the protein solutions. Protein concentration, bioactivity concentration $\left(\mathrm{AU} \cdot \mathrm{mL}^{-1}\right)$ and inhibitory spectrum were evaluated for each retentate and for the filtrate of the smallest porosity membrane.

\subsection{Preliminary characterisation of antimicrobial activity}

CFS from different culture incubation times as well as samples along the purification procedure were subjected to the action of proteinase K. The effect of catalase addition to CFS was also tested. Proteinase K (Sigma-Aldrich, Steinheim, Germany) was reconstituted in $0.05 \mathrm{~mol} \cdot \mathrm{L}^{-1}$ Tris- $\mathrm{HCl}$ pH 7.5 with $0.005 \mathrm{~mol} \cdot \mathrm{L}^{-1} \mathrm{CaCl}_{2}$ and immobilised catalase (Sigma-Aldrich) was treated according to manufacturers' instructions and resuspended in MRS broth. Neutralised samples were treated with $0.5 \mathrm{~g} \cdot \mathrm{L}^{-1}$ of each enzyme for $2 \mathrm{~h}$, at $37^{\circ} \mathrm{C}$ (proteinase $\mathrm{K}$ ) or $25^{\circ} \mathrm{C}$ (catalase). Proteinase $\mathrm{K}$ was inactivated by heating solutions at $100{ }^{\circ} \mathrm{C}$ for $5 \mathrm{~min}$. Non-treated samples as well as blanks were exposed to the same conditions. Immobilised catalase was eliminated from the solution by centrifugation. Enzyme buffer, heat-inactivated proteinase $\mathrm{K}$ and MRS treated with catalase were used as blanks. Nisin was also used as positive control for proteinase $\mathrm{K}$ activity. After enzyme treatment, the residual bioactivity was determined by the well diffusion assay.

Heat stability was tested by submitting the proteinaceous fraction (see below) at $100{ }^{\circ} \mathrm{C}$ for increasing time intervals, after which bioactivity was tested quantitatively. Sample stability at $4{ }^{\circ} \mathrm{C}$ and $-20{ }^{\circ} \mathrm{C}$ was also evaluated in the same way for sterile CFS and proteinaceous fraction.

\subsection{Purification attempts of bacteriocin-like compounds}

CFS was prepared from a $12 \mathrm{~h}$ incubation culture as described above. Antimicrobial proteins were isolated by overnight precipitation with $75 \%$ saturation $\left(\mathrm{NH}_{4}\right)_{2} \mathrm{SO}_{4}$ (Riedel-deHaën, Seelze, Germany) at $4{ }^{\circ} \mathrm{C}$ with slight agitation. Pellets were separated by centrifugation at $10000 \mathrm{~g}$ for $60 \mathrm{~min}$ at $0{ }^{\circ} \mathrm{C}$, and resuspended in the smallest feasible volume of bidistilled water. Elimination of salt and other low molecular mass compounds was achieved by dialysing this fraction through a membrane of $3.5 \mathrm{~kg} \cdot \mathrm{mol}^{-1}$ cut-off (SnakeSkin, Pierce, Rockford, USA) against large volumes of water. The 
suspension thus obtained has been designated as proteinaceous fraction (or crude bacteriocin-fraction). This fraction was injected into an anionic exchange column (Resource Q, Amersham Pharmacia Biotech AB, Uppsala, Sweden) in the FPLC System (Amersham Pharmacia Biotech AB). A stepwise salt gradient was applied by the use of Buffer A: Tris- $\mathrm{HCl} 0.01 \mathrm{~mol} \cdot \mathrm{L}^{-1} \mathrm{pH} 6.0$ and Buffer B: A + $1 \mathrm{~mol} \cdot \mathrm{L}^{-1} \mathrm{NaCl}$. Active fractions were further concentrated by ethanol precipitation $1: 4$ for $2 \mathrm{~h}$ at $0{ }^{\circ} \mathrm{C}$. Pellets were recovered by centrifugation at $10000 \mathrm{~g}$ for $15 \mathrm{~min}$ at $0{ }^{\circ} \mathrm{C}$. After elimination of ethanol residues by air drying, pellets were resuspended in the minimum feasible volume of $0.01 \mathrm{~mol} \cdot \mathrm{L}^{-1}$ Tris- $\mathrm{HCl} \mathrm{pH} 6.0$ and injected for a second chromatographic step into the same column. At each purification step samples were evaluated for bioactivity and protein content. Purification grade was monitored by polyacrylamide gel electrophoresis.

\subsection{Quantification of protein concentration}

For the quantification of protein content a modification of the Bradford method has been used, according to manufacturers' instructions for micro-assay procedure (Biorad Protein Assay, Bio-Rad Laboratories, Hercules-CA, USA).

\subsection{Polyacrylamide gel electrophoresis}

Evaluation of purification grade and estimation of molecular mass of isolated bacteriocin-like compounds has been performed by SDS-PAGE. Proteins and peptides of molecular mass larger than $20 \mathrm{~kg} \cdot \mathrm{mol}^{-1}$ has been visualised by the use of the technique described by Laemli [8], using SDS-PAGE kit low range (Bio-Rad Laboratories) as molecular mass standards. Low molecular mass peptides has been visualised by Tricine-SDS-PAGE, as described by Schagger and von Jagow [16], using the peptide marker kit (Amersham Pharmacia Biotech AB, Uppsala, Sweden) as molecular mass standards. Gels were silver-stained.

\section{RESULTS}

\subsection{Quantification of antibacterial activity}

The critical dilution method is the most often described method for the quantification of bacteriocin activity. It is based on the two-fold sequential dilution of the sample, followed by a well diffusion assay or spot test against a selected sensitive strain. Usually, bacteriocin titres have been estimated directly from the first dilution where inhibition is not observed and results are expressed in arbitrary units of concentration $\left(\mathrm{AU} \cdot \mathrm{mL}^{-1}\right)$. This is a practical method for bioactivity evaluation of unknown antibacterial substances but it results in a geometric discontinuous scale in which subjective errors may be considerably amplified. Thus, in highly concentrated samples (as during purification) the activity is overestimated mainly because there will be a large number of non-evaluated dilutions between the last one showing inhibition and the one that is considered. In order to minimise this error, the model herein used is based on the linear relationship between the area of inhibition zone $\left(\mathrm{mm}^{2}\right)$ and $\log _{10}$ of dilution factor of the sample (Fig. 1) and it is based on the following assumptions:

- There are no limitations to diffusion caused by agar or by any other medium component.

- The aqueous solution added to each well diffuses into agar equally in all directions forming a cylindrical volume.

- The antimicrobial substances diffuse in that volume with no constraints, resulting in a concentration gradient from the well wall to the external border of the diffusion zone.

- Sensitive indicator strain grows over the antimicrobials concentration gradient 


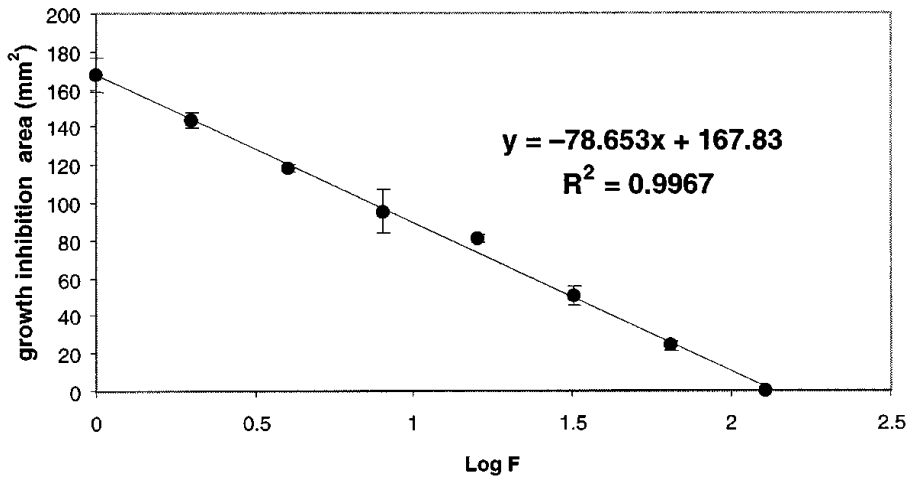

Figure 1. Critical dilution estimation from regression. Linear model relating the area of inhibition zone (obtained from the action of the sample over a sensitive organism) to the log of sample dilution factor. Quantification of sample bioactivity is based on abscissa intercept. until minimum inhibitory concentration is achieved corresponding to a clear circular inhibition area around the well, specific for each dilution. When the sample is successively diluted, inhibition zones decrease until critical dilution is achieved, when no inhibition of the sensitive organism occurs.

- Only a diffusional process takes place and there is no evaporation of the liquid from the wells.

- Experimental conditions are the same in every assay, e.g. well diameter, sample volume, thickness and moisture of the agar (including overlay), number of viable cells in overlay, temperature, time and other conditions for diffusion and incubation.

In the present work, the bioactivity of each sample was determined analytically by linear regression, using the equation: $A=a+b \log F$. In this equation, $A$ is the area of the inhibition zone $\left(\mathrm{mm}^{2}\right)$ calculated, for each dilution, after the average of diameter measurements; $F$ is the dilution factor (reciprocal of each dilution) and $a$ and $b$ are constants. The bioactivity of the sample is the dilution factor that corresponds to the abscissa intercept, multiplied by the factor 1 000/38 and expressed in AU.mL ${ }^{-1}$. Note that in calculations it is possible to use the area of the inhibition zone instead of the volume of the hollow cylinder because the thickness of the agar and the well diameter are assumed as constants.
The calculation of the critical dilution from the abscissa intercept relies on several experimental points and so it is more precise than the usual procedure based on the visual observation of a single dilution. Nuñez et al. [11] compared the direct estimation of critical dilution with regression procedures based on diameter and area of growth inhibition zones. Based on variance analysis of results, these authors concluded that the common procedure of direct estimation of critical dilution is far more subjective and inaccurate than the procedures based on regression.

As can be seen from Figure 1, the determination coefficient $\left(r^{2}\right)$ is 0.997 , which means that more than $99.7 \%$ of total variation in bioactivity can be explained by the current regression. This procedure has been applied to numerous samples of a broad range of bioactivity concentration always resulting in values of $r^{2}>0.95$.

\subsection{Preliminary characterisation of antimicrobial activity}

The antagonistic activity present in culture supernatant was found to be thermostable (see below) and maintained at pH 6.5 (eliminating possible inhibition due to undissociated lactic acid). The bioactivity of CFS was eliminated by the action of proteinase $\mathrm{K}$ and it was not altered by the action 
of catalase (eliminating possible inhibition due to hydrogen peroxide). It was also found to be precipitable with ammonium sulphate and retained by ultrafiltration and dialysis (see below). Thus, the bioactivity found is consistent with the presence of at least one bacteriocin, since it matches the general characteristics of bacteriocins of LAB [1].

It was verified that the activity of the proteinaceous fraction (crude bacteriocin-like compounds) did not noticeably decrease upon exposure to $100{ }^{\circ} \mathrm{C}$ for $60 \mathrm{~min}$. Sterile samples of CFS and its proteinaceous fraction were also preserved at $-20{ }^{\circ} \mathrm{C}$ and $4{ }^{\circ} \mathrm{C}$ for three months without noticeable loss of activity. Thus, the bioactive proteins produced by $L$. plantarum LB17.2b seem to be very stable under refrigeration conditions and highly heat resistant.

The inhibitory action of 500 AU of the proteinaceous fraction was tested against a total of 93 strains of natural competitors of L. plantarum and other Gram-positive and Gram-negative bacteria (Tab. I). As can be seen from Table I, about $70 \%$ of the tested LAB strains were inhibited while from the other bacterial groups only Enterococcus faecalis was inhibited. Also, no inhibition of strains of the genus Listeria or of Gramnegative bacteria was observed (Tab. I). Thus, the antimicrobial proteins produced during the growth of L. plantarum LB17.2b seem to have a narrow inhibitory spectrum including only bacteria related to the producer. The observed antagonism seems to be more strain-specific rather than speciesor genus-specific.

\subsection{Production of antimicrobial compounds}

The production kinetics of antimicrobial proteins of $L$. plantarum LB 17.2 b was examined in batch under uncontrolled $\mathrm{pH}$ conditions. It was observed that after the lag phase, exponential growth took place for approximately $5 \mathrm{~h}$ at a maximum specific growth rate of $0.37 \mathrm{~h}^{-1}$, corresponding to a duplication time of $1.89 \mathrm{~h}$. After $24 \mathrm{~h}$ of incubation, growth had totally stopped and medium $\mathrm{pH}$ was stabilised by 3.5-3.7.

As can be seen from Figure 2, the production of the referred bioactive compounds roughly paralleled that of biomass. Its accumulation in the medium was maximal after about $12 \mathrm{~h}$ of incubation succeeding the decrease in growth rate during the transition to the stationary phase. It was also observed that upon further fermentation, bioactivity dropped by more than $80 \%$ after $24 \mathrm{~h}$ and by about $95 \%$ after $72 \mathrm{~h}$ (see Tab. II). In all samples activity was eliminated by the action of proteinase $\mathrm{K}$, and not affected by catalase, suggesting bioactivity to be associated with proteinaceous compounds.

\subsection{Ultrafiltration studies}

CFS prepared from culture media of different fermentation times was subjected to sequential ultrafiltration through membranes of decreasing porosity in order to separate small solutes from macromolecules and to observe the influence of different fractions in bioactivity. In most cases activity was recovered only in the retentates of the $30 \mathrm{~kg} \cdot \mathrm{mol}^{-1}$ cut-off membranes. As can be seen from Table II, only two exceptions were registered, referring to a slight activity in retentates of 10 and $3 \mathrm{~kg} \cdot \mathrm{mol}^{-1}$ cut-off membranes, corresponding to CFS of $72 \mathrm{~h}$ and $48 \mathrm{~h}$ incubation, respectively. As above, bioactive samples were inactivated by proteinase K. Thus, the retained bioactive compounds are expected to be of proteinaceous nature. On the other hand, no activity was found in filtrates of the of $3 \mathrm{~kg} \cdot \mathrm{mol}^{-1}$ cut-off membrane, even after ten-fold concentration by lyophilisation. Consequently, there is no evidence of the existence of low molecular mass metabolites, thermostable and active at neutral $\mathrm{pH}$ values.

The retention pattern observed indicates that the smallest active unit has a molecular mass between 3 and $10 \mathrm{~kg} \cdot \mathrm{mol}^{-1}$. 
Table I. Inhibitory spectrum of bacteriocins of Lactobacillus plantarum LB17.2b ${ }^{\mathrm{a}}$.

\begin{tabular}{|c|c|}
\hline Indicator species & nb. inhibited strains/nb. tested strains \\
\hline \multicolumn{2}{|c|}{ Gram-positive bacteria - lactic acid bacteria: } \\
\hline Lactobacillus plantarum & $9 / 12$ \\
\hline Lactobacillus homohiochii & $2 / 2$ \\
\hline Lactobacillus fermentum & $1 / 1$ \\
\hline Lactobacillus acidophilus & $1 / 1$ \\
\hline Lactobacillus salivarius & $0 / 1$ \\
\hline Lactobacillus pentosus & $9 / 11$ \\
\hline Lactobacillus graminis & $4 / 6$ \\
\hline Lactobacillus paracasei & $7 / 10$ \\
\hline Lactobacillus brevis & $1 / 1$ \\
\hline Lactobacillus rhamnosus & $2 / 2$ \\
\hline Lactobacillus sake & $0 / 2$ \\
\hline Lactobacillus coryniformis & $0 / 2$ \\
\hline Lactobacillus maltaronicus & $1 / 1$ \\
\hline Lactobacillus curvatus & $0 / 2$ \\
\hline Lactobacillus agilis & $1 / 1$ \\
\hline Lactobacillus jensenii & $0 / 1$ \\
\hline Lactobacillus sanfrancisco & $1 / 1$ \\
\hline Lactobacillus casei & $1 / 1$ \\
\hline Lactobacillus alimentaris & $1 / 2$ \\
\hline Lactobacillus viridescens & $0 / 1$ \\
\hline Weissella confusa & $6 / 8$ \\
\hline Weissella paramesenteroides & $1 / 1$ \\
\hline Weissella kandleri & $0 / 1$ \\
\hline \multicolumn{2}{|c|}{ Gram-positive bacteria - spoilage bacteria: } \\
\hline Enterococcus faecalis & $1 / 1$ \\
\hline Staphylococcus viridans & $0 / 1$ \\
\hline Staphylococcus aureus & $0 / 1$ \\
\hline Staphylococcus carnosus & $0 / 1$ \\
\hline Listeria inпосиа & $0 / 1$ \\
\hline Listeria monocytogenes & $0 / 2$ \\
\hline \multicolumn{2}{|c|}{ Gram-negative bacteria - human pathogens: } \\
\hline Escherichia coli & $0 / 4$ \\
\hline Pseudomonas aeruginosa & $0 / 1$ \\
\hline Pseudomonas sp. & $0 / 1$ \\
\hline Klebsiella pneumoniae & $0 / 9$ \\
\hline
\end{tabular}

a Inhibitory studies were carried out by spot test. Each drop of crude bacteriocin-fraction contained $500 \mathrm{AU}$ of activity and was obtained from CFS after $12 \mathrm{~h}$ incubation.

It can also be seen from Table II that activity decreases with fermentation time as expected from previous results. On the other hand, it was verified that the total activity recovered in all retentates of highest porosity membrane was about twice the activity that was applied to the membrane (CFS). When the correspondent filtrate was added in equal parts to each of those retentates the activity decreased more than twofold, suggesting the existence of a filterable inhibitor in CFS. 


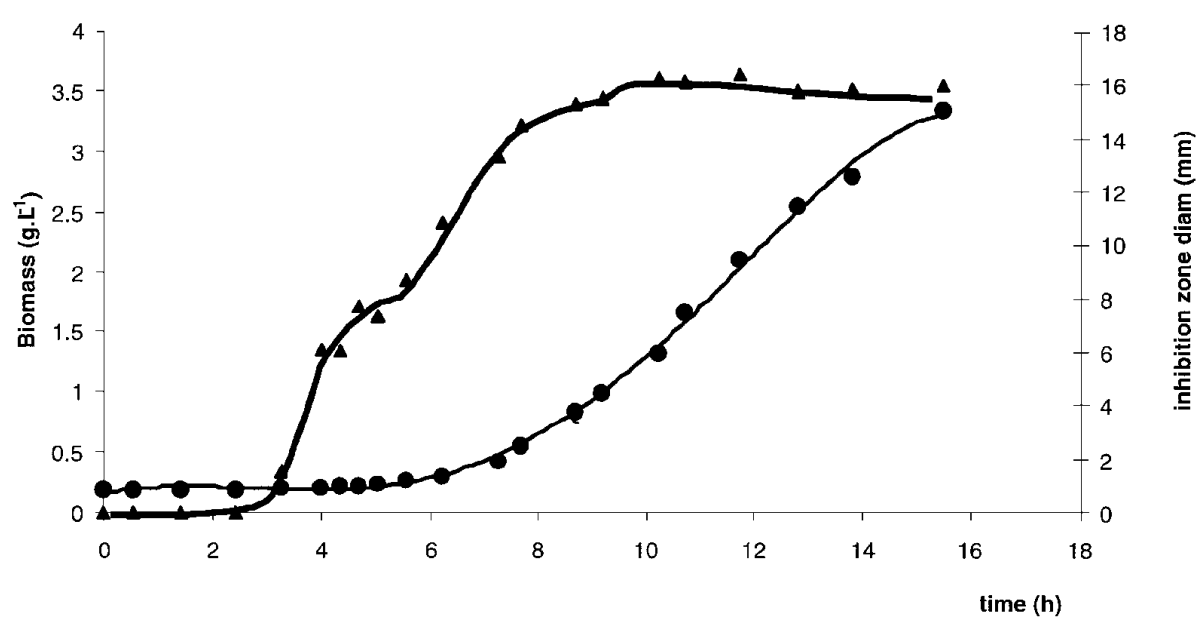

Figure 2. Accumulation of heat stable bioactive compounds in growth medium during culture growth (batch). The activity was monitored as the diameter of inhibition zone $(\mathrm{mm})$ over the indicator strain Weissella paramesenteroides DSM20288 (A) and biomass was expressed in $\mathrm{g} \cdot \mathrm{L}^{-1}$ of dry weight $(\boldsymbol{)})$.

Table II. Sequential ultrafiltration of culture supernatants of different incubation times through membranes of decreasing porosities.

\begin{tabular}{|c|c|c|c|c|c|}
\hline \multicolumn{6}{|c|}{ AU of total activity (\% initial activity recovered) } \\
\hline \multirow{2}{*}{$\begin{array}{l}\text { Fermentation } \\
\text { time }(\mathrm{h})\end{array}$} & \multirow{2}{*}{$\begin{array}{c}\begin{array}{c}\text { Initial activity } \\
(\mathrm{AU})\end{array} \\
\mathrm{CFS}^{\mathrm{a}}\end{array}$} & \multicolumn{4}{|c|}{ membrane cut-off $\left(\mathrm{kg} \cdot \mathrm{mol}^{-1}\right)$} \\
\hline & & $30^{\mathrm{b}}$ & & $10^{\mathrm{b}}$ & $3^{\mathrm{b}}$ \\
\hline 12 & 1707780 & 2954359 & (173) & 0 & 0 \\
\hline 24 & 202080 & 288594 & $(143)$ & 0 & 0 \\
\hline 48 & 173940 & 425320 & (245) & 0 & $0.5(<0.001)$ \\
\hline 72 & 96600 & 291103 & (301) & $0.6(<0.001)$ & 0 \\
\hline
\end{tabular}

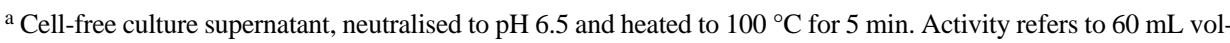
ume (divided by 6 devices).

${ }^{\mathrm{b}}$ Total activity refers to retentate only and it was calculated upon the total recovered volume on all membranes of each cut-off.

The active fractions were tested against several Lactobacillus strains as well as against some Gram-negative bacterial strains. Although total bioactivity seems to decrease with fermentation time, the activity spectrum seems to become wider (Tab. III). It is important to notice that bioactivity, as was defined, is an arbitrary measure based on the inhibition of a single bacterial strain. Thus, Weissella paramesenteroides DSM20288 (indicator strain) is highly sensitive to the component that is produced during the exponential phase, but its sensitivity to other bacteriocin-like compounds may 
Table III. Differences in activity spectrum of bacteriocin-fractions obtained by ultrafiltration of supernatants from different culture incubation times.

\begin{tabular}{lcccc}
\hline Test organism & $12 \mathrm{~h}$ & $24 \mathrm{~h}$ & $48 \mathrm{~h} 72 \mathrm{~h}$ \\
\hline Lactobacillus pentosus L2 & 0 & + & + & + \\
Lactobacillus pentosus L5 & 0 & + & 0 & + \\
Lactobacillus graminis L7 & 0 & + & + & + \\
Lactobacillus plantarum L12 & + & + & + & + \\
Lactobacillus plantarum L15 & + & + & + & +
\end{tabular}

a $100 \mathrm{AU}$ of each retentate of the $30 \mathrm{~kg} \cdot \mathrm{mol}^{-1}$ cut-off membrane were applied over each culture by spot-test. + : Inhibition.

0 : Absence of inhibition.

not be the same. Therefore, these results can be explained by the accumulation in culture medium of a different protein towards which the indicator strain shows a reduced sensitivity.

The activity spectrum of neutral samples of these retentates included only LAB but when the same samples were acidified with lactic acid to $\mathrm{pH} 3.7$ inhibition of Klebsiella pneumoniae k606 was observed in retentates of all fermentation times. In addition, retentates obtained from CFS of 48 and $72 \mathrm{~h}$ (pH 3.7) also inhibited Escherichia coli v1 and Pseudomonas sp. v1. None of these strains were inhibited by the control (MRS acidified with lactic acid to $\mathrm{pH}$ 3.7) under the conditions of the test. Inhibition of Gram-negative bacteria was also observed in preliminary tests carried out with non-neutralised supernatants of long incubation time (pH 3.7), concentrated by lyophilisation. Notice that activity of CFS and retentates has been shown to be eliminated by the action of proteases and apparently the amount of lactic acid that has been used in the tests was not inhibitory for the referred strains. As a consequence, the observed inhibition of Gram-negatives cannot be explained by the action of $\mathrm{pH}$ or by the presence of lactic acid only.

\subsection{Purification attempts}

Isolation of bacteriocin-like compounds from CFS was accomplished by ammonium sulphate precipitation. No activity was recovered in pellets by the addition of $20 \%$ of saturation level of ammonium sulphate but active pellets were recovered upon the stepwise addition of the salt, from 30 to $80 \%$. Activity was optimally recovered in a pellet at a saturation level of $60 \%$, although to improve recovery, a concentration of $75 \%$ (saturation level of the salt) was used. Desalting and further purification were carried out by dialysis. Each of these steps corresponded to a two-fold purification grade, resulting in an active proteinaceous fraction. No activity was recovered upon injection of this fraction into cationic exchange or gel filtration columns, although several systems had been tried out. On the other hand, it was possible to recover the activity and to identify two different active proteins by anionic exchange chromatography. Thus, after the first ionic exchange step, two active peaks were recovered: fraction I (eluted at $0.1-0.45 \mathrm{~mol} \cdot \mathrm{L}^{-1} \mathrm{NaCl} ; 7$ to $12 \mathrm{~min}$ retention time) and fraction II (eluted at $0.5-0.6 \mathrm{~mol} \cdot \mathrm{L}^{-1}$ $\mathrm{NaCl} ; 14$ to 17 min retention time). By ethanol precipitation both fractions produced active pellets. Fraction I was then further fractionated by a second anionic exchange step resulting in an active peak (fraction III) that corresponded to a single band in SDS-PAGE (Fig. 3). Since SDS is a chaotropic agent, the isolated band that was identified in the gel (Fig. 3) probably corresponds to a single molecular unit. Its molecular mass was then estimated to be around 50 to $60 \mathrm{~kg} \cdot \mathrm{mol}^{-1}$. As can be seen from Figure 3, the activity of fraction II corresponds to a lower molecular weight peptide although it has not been completely isolated to date.

\section{DISCUSSION}

Lactic acid bacteria synthesise bactericidal agents that vary in their spectrum of 


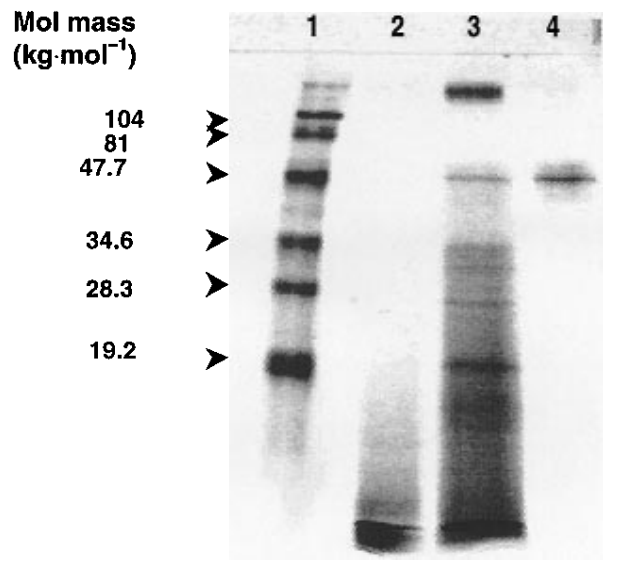

Figure 3. SDS-PAGE. Lane 1: molecular mass standards (kit Biorad low range); lane 2: bioactive peptide (fraction II); lane 3: supernatant (CFS); lane 4: bioactive isolated polypeptide (fraction III).

activity. Many of these agents are proteinaceous compounds while others are primary metabolites or other non-identified by-products [13].

The strain L. plantarum LB17.2b was isolated from fermenting olive brines and it has been shown to produce bacteriocinlike compounds that are active against their natural competitors. The inhibitory spectrum of the proteinaceous fraction (crude bacteriocin-like compounds) herein described, resembles that of Plantaricin S [6] although this fraction is assumed to contain the two distinct bioactive compounds that have been detected during purification attempts. In both cases Enterococcus strains are inhibited and no inhibition of Listeria was observed.

On the other hand, based on the differences observed in the activity spectrum obtained with extracts from long culture incubation times, another late produced proteinaceous compound was detected. The bioactivity detection method based on the inhibition of Weissella paramesenteroides DSM20288 was found to be ineffective for the detection of this compound. JiménezDiaz et al. [6] also found two bacteriocins (Plantaricin S and T) that were produced at different phases of culture growth. For the detection and quantification of each of those bacteriocins they had to use two different indicator strains. Also for subsequent studies on the late produced compound, mentioned in the present work, one of the three first strains listed in Table III will be chosen as indicator organism. Concerning the largest isolated polypeptide $\left(50 \mathrm{~kg} \cdot \mathrm{mol}^{-1}\right)$, it seems to correspond to the primary metabolite detected since a band in that position is consistently observed in SDS gels of samples from the exponential growth phase. Also Plantaricin S [6] and Amylovorin L471 [2] presented a primary metabolite kinetics.

A discrepancy was found between the inhibitory spectrum of some crude extracts of L. plantarum LB17.2b as well as acidified $30 \mathrm{~kg} \cdot \mathrm{mol}^{-1}$ retentates and the inhibitory spectrum of the crude bacteriocin-fraction, namely in the inhibition of Gram-negative bacterial strains. A wider inhibitory spectrum was observed only in the presence of lactic acid. Thus, one possible explanation could be the interaction of proteinaceous compounds with lactic acid. Either these proteinaceous compounds are more active towards certain strains at low $\mathrm{pH}$ values, or the presence of organic acids, such as lactic acid, can increase the sensitivity of cells to the action of these polypeptides. This anomalous activity spectrum seems to be correlated with culture age. The overall activity of this strain seems to be biochemically adapted to low $\mathrm{pH}$ media as occurs in fermentation substrates from where the producer culture was isolated. Other authors also registered similar results on preliminary evaluation of crude extracts [3, 18]. Fricourt et al. [3] described an antibacterial substance, named Plantaricin F, with an estimated molecular mass between 470 and $6770 \mathrm{~g} \cdot \mathrm{mol}^{-1}$, active only at $\mathrm{pH}$ values lower than 4.5 and showing a wide inhibitory spectrum that included Gram-negatives. Also, Vignolo et al. [18] detected a wide inhibitory 
spectrum of a L. plantarum culture supernatant, which also includes Gram-negatives. Apparently, the substance (named Lactocin 705) showed a decrease in activity (towards indicator strain) when the $\mathrm{pH}$ of the crude extract was adjusted to 6.5 . The authors of both works based their assumptions on preliminary studies of crude extracts. In none of the cases have the substances been isolated. In some circumstances, we observed a marked difference between the inhibitory spectrum of crude extract and its proteinaceous fraction (crude bacteriocin-like compounds), namely in acidic conditions. The hypothesis that the inhibition attributed to Plantaricin F and Lactocin 705 is caused by the interaction of two or more metabolites cannot be excluded. It is then important to distinguish between overall culture inhibitory capacity and bacteriocin inhibitory spectrum. This last can only be correctly evaluated after some purification steps. Typically, bacteriocins produced by Lactobacillus are described to be active only against closely related bacteria [1, 13].

The fact that most of the activity of the extract has been retained in the $30 \mathrm{~kg} \cdot \mathrm{mol}^{-1}$ cut-off membrane correlates with the observations made during purification. In fact, we have isolated a bioactive proteinaceous compound with a molecular mass of about $50 \mathrm{~kg} \cdot \mathrm{mol}^{-1}$ that is believed to be highly thermostable. The properties of this compound fulfil that of some bacteriocin definitions $[5,7,13]$ but if its molecular mass is confirmed by more precise instrumental analytical methods it does not seem to fit into any of the classes accepted for LAB bacteriocins [10]. As mentioned above, we also detected the presence of at least one other bioactive compound of molecular mass apparently smaller than $10 \mathrm{~kg} \cdot \mathrm{mol}^{-1}$. Therefore it seems that the currently studied strain produces more than one antibacterial proteinaceous compound.

The strain of $L$. plantarum LB17.2b possesses the ability to inhibit its natural competitors, possibly including pathogens and olive spoilage organisms. Since the antagonism refers to the inhibition of other organisms caused by competition for nutrients and by the production of antimicrobial metabolites [4], then L. plantarum LB17.2b seems to hold important "tools" for overgrowing wild flora, as is desirable for a starter culture. Ruiz-Barba et al. [15] inoculated an olive brine with a $L$. plantarum strain that was previously identified as a bacteriocin producer and they verified that this strain became readily dominant over wild bacteria. The same behaviour was not reproduced by the non-bacteriocin-producer mutant. Also Vogel et al. [19] described similar results in fermenting sausages that have been inoculated with $L$. curvatus .

\section{ACKNOWLEDGEMENTS}

The authors are grateful to Prof. A. Duarte and Dr. A. Ramos for their kind offer of cultures of spoilage bacteria and hospital isolates of human pathogens.

This work was partially supported by grant: Praxis XXI/BD/21528/99 (FCT).

\section{REFERENCES}

[1] de Vuyst L., Vandamme E.J., Lactic acid bacteria, bacteriocins and their practical importance, in: De Vuyst L., Vandamme E.J. (Eds.), Bacteriocins of Lactic Acid Bacteria: Microbiology, Genetics and Applications, Blackie Academic \& Professional, London, UK, 1994, pp. 1-11.

[2] de Vuyst L., Callewaert R., Pot B., Characterization of the antagonistic activity of Lactobacillus amylovorus DCE 471 and large scale isolation of its bacteriocin amylovorin L471, Syst. Appl. Microbiol. 19 (1996) 9-20.

[3] Fricourt B.V., Barefoot S.F., Testin R.F., Hayasaka S.S., Detection and activity of plantaricin $\mathrm{F}$ an antibacterial substance from $\mathrm{Lac}$ tobacillus plantarum BF001 isolated from processed channel catfish, J. Food Prot. 57 (1994) 698-702.

[4] Holzapfel W.H., Geisen R., Schillinger U., Biological preservation of foods with reference to protective cultures, bacteriocins and food grade enzymes, Int. J. Food Microbiol. 24 (1995) 343-362. 
[5] Jack R.W., Tagg J., Ray B., Bacteriocins of Gram-positive bacteria, Microbiol. Rev. 59 (1995) 171-200.

[6] Jiménez-Diáz J., Rios-Sánchez R.M., Desmazeaud M., Ruiz-Barba J.L., Piard J.C., Plantaricins $\mathrm{S}$ and $\mathrm{T}$, two new bacteriocins produced by Lactobacillus plantarum LPCO10 isolated from a green olive fermentation, Appl. Environ. Microbiol. 59 (1993) 1416-1424.

[7] Klaenhammer T.R., Genetics of bacteriocins produced by lactic acid bacteria, FEMS Microbiol. Rev. 12 (1993) 39-86.

[8] Laemli U.K., Cleavage of structural proteins during the assembly of the head of bacteriophage T4, Nature 227 (1970) 680-685.

[9] Mayr-Harting A., Hedjes A.J., Berkeley R.C.W., Methods for studying bacteriocins, in: Norris J.R., Ribbons D.W. (Eds.), Methods in Microbiology, Vol. 7A, Academic Press, New York, USA, 1972, pp. 315-422.

[10] Moll G.N., Konings W.N., Driessen A., Bacteriocins: mechanism of membrane insertion and pore formation, Antonie van Leeuwenhoek 76 (1999) 186-198.

[11] Nuñez M., Tomillo J., Gaya P., Medina M., Bacteriocin quantification by the critical dilution method: a comparison of arbitrary units with diameter and area of the zone of growth inhibition, Milchwissenschaft 51 (1996) 7-10.

[12] Piard J.C., Desmazeaud M., Inhibiting factors produced by lactic acid bacteria. 1. Oxygen metabolites and catabolism end products, Lait 71 (1991) 525-541.
[13] Piard J.C., Desmazeaud M., Inhibiting factors produced by lactic acid bacteria. 2 . Bacteriocins and other antibacterial substances, Lait 72 (1992) 113-142.

[14] Roger S., Ingraham J.L., Whellis M.L., Painter P.R., The Microbial World, Prentice-Hall, New Jersey, USA, 1986.

[15] Ruiz-Barba J.L., Cathcart D.P., Warner P.J., Jimenez-Diaz R., Use of Lactobacillus plantarum LPCO10, a bacteriocin producer, as a starter culture in Spanish-style green olive fermentations, Appl. Environ. Microbiol. 60 (1994) 2059-2064.

[16] Schagger H., von Jagow G., Tricine-SodiumDodecyl-Sulphate-polyacrylamide gel electrophoresis for the separation of proteins in range from 1 to $100 \mathrm{kDa}$, Anal. Biochem. 166 (1987) 368-379.

[17] Talarico T.L., Casas I.A., Chung T.C. Dobrogosz W.J., Production and isolation of reuterin, a growth inhibitor produced by Lactobacillus reuteri, Antimicrob. Agents Chemother. 32 (1988) 1854-1858.

[18] Vignolo G.M., Suriani F., Holgado A.P.R., Oliver G., Antibacterial activity of Lactobacillus strains isolated from dry fermented sausages, J. Appl. Bacteriol. 75 (1993) 344-349.

[19] Vogel R.F., Pohle B.S., Tichaczek P.S., Hammes W.P., The competitive advantage of Lactobacillus curvatus LTH 1174 in sausage fermentations is caused by formation of curvacin A, Syst. Appl. Microbiol. 16 (1993) 457-462 